\title{
Onset of intermittent flow: Visualization of flow structures
}

\author{
Abderraouf Arabi ${ }^{1,2,}{ }^{*}$, Yacine Salhi ${ }^{2}$, Amina Bouderbal $^{2}$, Youcef Zenati ${ }^{2}$, El-Khider Si-Ahmed ${ }^{3}$, and Jack Legrand ${ }^{3}$ \\ ${ }^{1}$ Direction Centrale Recherche et Développement, SONATRACH, Avenue 1er Novembre, 35000 Boumerdes, Algeria \\ ${ }^{2}$ Laboratory of Theoretical and Applied Fluid Mechanics, LMFTA, University of Sciences and Technology Houari Boumediene \\ USTHB, Physics' Faculty, BP 32 El Alia, Bab Ezzouar, 16111 Algiers, Algeria \\ ${ }^{3}$ GEPEA, ONIRIS, CNRS, UMR-6144, University of Nantes, 37 Bd de l'Université, BP406, 44602 Saint-Nazaire, France
}

Received: 18 November 2020 / Accepted: 1 March 2021

\begin{abstract}
The transition from stratified to intermittent air-water two-phase flow was investigated experimentally, by flow visualization and pressure drop signals analyses, in a $30 \mathrm{~mm}$ ID pipe. The intermittent flow's onset was found to be mainly dependent on the liquid superficial velocity and the pipe diameter. Plug flow, Less Aerated Slug (LAS) or Highly Aerated Slug (HAS) flows could be obtained on the gas superficial velocity grounds. The available models, compared to experiments, could not predict adequately the intermittent flow onset. The appearance of liquid slugs was revealed by peaks in the pressure drop signal. Furthermore, it was shown that the available slug frequency correlations were not valid in the zone of the onset of intermittent flow.
\end{abstract}

\section{Nomenclature}

$\begin{array}{ll}C & \text { Variable }[-] \\ D & \text { Pipe diameter }[\mathrm{m}] \\ f & \text { Frequency }[\mathrm{Hz}] \\ \mathrm{Fr} & \text { Froude number }[-] \\ g & \text { Gravitationnal acceleration }\left[\mathrm{m} \mathrm{s}^{-2}\right] \\ \text { HAS } & \text { Highly Aerated Slug } \\ \text { ID } & \text { Internal diameter } \\ \text { LAS } & \text { Less Aerated Slug } \\ \text { PSD } & \text { Power Spectral Density } \\ \text { St } & \text { Strouhal number [-] } \\ X & \text { Lockhart-Martinelli parameter }[-]\end{array}$

\section{Greeks letters}

$\begin{array}{ll}\lambda & \text { Input fraction }[-] \\ \rho & \text { Density }\left[\mathrm{Kg} \mathrm{m}^{-3}\right]\end{array}$

\section{Subscripts}

$\begin{array}{ll}G & \text { Gas } \\ L & \text { Liquid } \\ s & \text { Slug } \\ S & \text { Superficial }\end{array}$

\footnotetext{
* Corresponding author: arabi.abderraouf@sonatrach.dz
}

\section{Introduction}

In oil and gas industry, gas-liquid two-phase flows are present in wells [1] and in the surface production equipments. According to the operating conditions (pressure, temperature, liquid and gas superficial velocities, pipe orientation, and fluid properties) [2], both phases will be distributed in a certain topology called flow pattern. The knowledge of the latter is required for a better estimation of the hydrodynamics, thermal properties [3], choice of models closures in transient multiphase flow simulation codes [4, 5], as well as for the modeling of flow assurance phenomena such as wax deposition [6].

For low superficial velocities, in horizontal or slightly inclined pipe, the standard flow pattern is usually stratified. Compared to others regimes, the latter appears to be easier in modeling void fraction and pressure drop [7]. An increase of the liquid superficial velocity leads to a transition from stratified flow to intermittent flow [8]. The latter is characterized by alternate and random succession of two structures (gas pocket on a liquid film and liquid slug) [9].

The interface of liquid slugs and gas pockets can exhibit various shapes, and liquid slugs can display different levels of aerations, resulting in several types of intermittent flows, called sub-regimes. Intermittent flows have been classified in three sub-regimes: Plug flow, Less Aerated Slug flow (LAS flow) and Highly Aerated Slug flow (HAS flow) [10-13]. The hydrodynamic behavior of each sub-regime is different $[11,13]$ and requires to be modeled separately. The distinction between the different sub-regimes has been 
often ignored and was referred to, in some cases, as slug flow [13], leading then to a less rigorous approach of the phenomena.

The intermittent regime generates several operational problems, including liquid overflow downstream the set-up, amplification of pipes erosion-corrosion phenomena, and significant pressure drop [14]. Therefore, it is recommended dimensioning industrial installations to avoid slug formation [15]. Thus, understanding the mechanisms and parameters influencing the transition from stratified to intermittent flow, called onset of intermittent flow, is crucial.

In horizontal pipelines, liquid slugs are created under the action of the hydrodynamic slugging mechanism as explained by Dukler and Hubbard [16] and Taitel and Dukler [17] from visual observations in a pipe of $37.5 \mathrm{~mm}$ internal diameter and $19.8 \mathrm{~m}$ length. The onset of a slug is due to the initiation of a disturbance, at the gas-liquid interface of the stratified flow, at the inlet of the pipe. The acceleration of the gas results in a pressure decrease upstream creating a suction force acting on the liquid layer, which will overcome gravity and surface tension. The rising liquid will form a wave, which will develop as a liquid slug.

From a theoretical point of view, the onset of intermittent flow gave rise to numerous works [8, 18-21] and the Taitel and Dukler model [19] remains a relevant reference. However, this model is not easy to implement since it uses graphical/iterative solution to determine the equilibrium liquid level in a pipeline, for a given set of flow conditions. To overcome this constraint, Cheng et al. [22] simplified the model by giving a condition for a non-stratified flow, which includes intermittent and annular flow. This transition is given by the following condition:

$$
\operatorname{Fr}_{\mathrm{SG}} \geq\left(\frac{1}{0.65+1.11 X^{0.6}}\right)^{2}
$$

where $\mathrm{Fr}_{\mathrm{SG}}$ and $X$ are the gas Froude number and the Lockhart-Martinelli parameter, respectively, given as follows:

$$
\begin{gathered}
\mathrm{Fr}_{\mathrm{SG}}=\frac{V_{\mathrm{SG}}}{\sqrt{g D}} \sqrt{\frac{\rho_{\mathrm{L}}}{\rho_{\mathrm{L}}-\rho_{\mathrm{G}}}}, \\
X=\frac{V_{\mathrm{SL}}}{V_{\mathrm{SG}}} \sqrt{\frac{\rho_{\mathrm{L}}}{\rho_{\mathrm{G}}}}
\end{gathered}
$$

With $V_{\mathrm{SG}}, V_{\mathrm{SL}}, \rho_{\mathrm{G}}, \rho_{\mathrm{L}}, D$ and $\mathrm{g}$ are the gas superficial velocity, liquid superficial velocity, gas density, liquid density, pipe's diameter and gravity, respectively.

Nevertheless, discrepancies remain between most of the above-mentioned studies and the lack of a complete model for the onset of intermittent flow prediction exist [12]. Experimental observations as well as measurements of some parameters are still necessary steps in the understanding of the transition from stratified to intermittent flow.

Weisman et al. [23], based on their own data and from the literature, showed that the stratified-to-intermittent flow can be correlated according to:

$$
\operatorname{Fr}_{\mathrm{SG}}=0.25\left(\frac{\rho_{\mathrm{L}}-\rho_{\mathrm{G}}}{\rho_{\mathrm{L}}}\right)^{0.5}\left(\frac{V_{\mathrm{SG}}}{V_{\mathrm{SL}}}\right)^{1.1} .
$$

Using air-water mixture in a $95 \mathrm{~mm}$ ID pipe, Fan et al. [24] showed that the mechanisms of slug initiation for low and high gas superficial velocities were different. Based on the measured values of liquid height, pipe diameter, mixture velocity and the location of slug initiation, Woods and Hanratty [25] showed the existence of three mechanisms for slug formation. Salhi [26] observed visually in a $40 \mathrm{~mm}$ ID pipe that the onset of slug flow occurs for high gas superficial velocities due to the increase of the gas-liquid wavy interface. Using a $26.05 \mathrm{~mm}$ ID pipe, Vaze and Banerjee [27] measured the critical liquid holdup for the onset of slug flow. An empirical correlation for predicting this parameter was also developed. The authors showed that there is no direct transition between stratified and plug flow in the proposed flow pattern map. These observations, were also made by Ghajar and Tang [28], Vaze and Banerjee [29] and Thaker and Banerjee [10], contradicting those reported by Hurlburt and Hanratty [20].

Bhagwat and Ghajar [30] proposed an empirical model for the transition from stratified to non-stratified flows. This model uses the same dimensionless number as the models of Taitel and Dukler [19] and Cheng et al. [22]. In horizontal configuration, the transition criterion is provided by:

$$
\mathrm{Fr}_{\mathrm{SG}} \geq\left(0.6+C_{2}\right) \exp \left(-C_{1} C_{2} X^{C_{3}}\right) X^{-C 4}
$$

with

$$
\begin{gathered}
C_{1}=1.3 \ln \left(\frac{D}{0.0254}\right)+2.5 \\
C_{2}=C_{4}^{0.65}, \\
C_{3}= \begin{cases}0.65\left(\frac{D}{0.0254}\right)^{-0.15}\left(\frac{\rho_{\mathrm{L}}-\rho_{\mathrm{G}}}{1000}\right) & \text { if } \rho_{\mathrm{L}}<1000 \mathrm{Kg} / \mathrm{m}^{3} \\
0.65\left(\frac{D}{0.0254}\right)^{-0.15} & \text { if } \rho_{\mathrm{L}} \geq 1000 \mathrm{Kg} / \mathrm{m}^{3}\end{cases} \\
C_{4}=0.2 \sqrt{\frac{0.0254}{D} .}
\end{gathered}
$$

By visualizing the different sub-regimes of the slug flow in a $25 \mathrm{~mm}$ pipe, Thaker and Banerjee [10] defined the onset of slug flow as a sub-regime of slug flow characterized by episodic appearance of slugs. Thaker and Banerjee [31] reported that the slug formation rate depends strongly on the liquid flow rate. The gas flow rate, on the other hand, plays a role in the aeration of liquid slugs. Meanwhile, authors observations were mainly restricted to the aeration phenomena of the formed slugs, without sub-regimes identification.

Dinaryanto et al. [32] identified three mechanisms for liquid slug formation: Wave Growth (WG), Wave Coalescence (WC) and Disturbances Waves (DW). The authors, in their experiment on a $26 \mathrm{~mm}$ ID pipe, reported the occurrence of WG at low gas superficial velocities; WC at high gas superficial velocities and DW at high liquid superficial velocities with one of the two mechanisms WG or WC. An increase in diameter caused a shift in the stratified/slug and pseudo-slug/slug flows transitions as 


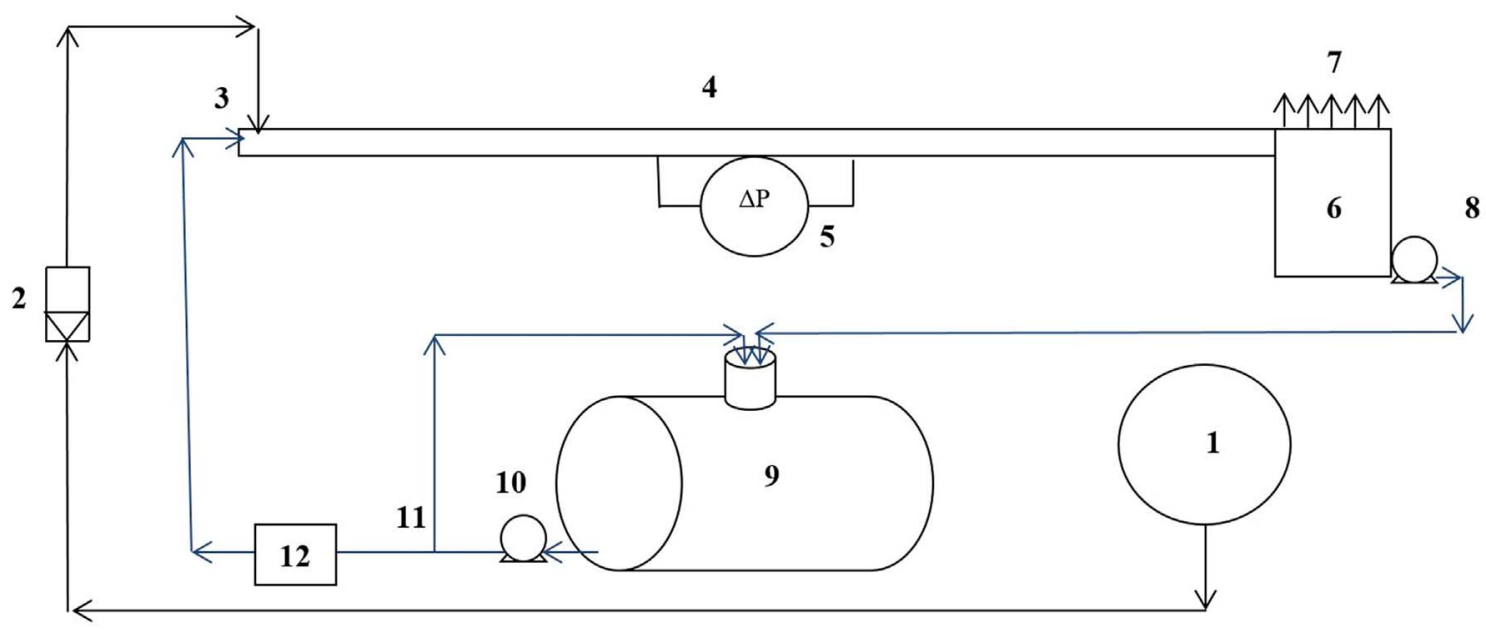

Fig. 1. Diagram of air-water flow loop. (1) compressor; (2) gas flowmeters; (3) T-mixer; (4) 30 mm ID pipe; (5) differential pressure transducer, (6) decantation tank; (7) air outlet; (8) pump; (9) liquid tank, (10) pump; (11) by-pass; (12) ultrasonic flowmeter.

reported by Deendarlianto et al. [12]. In addition, the authors pointed out that WG is responsible for the transition from stratified to plug and Less Aerated Slug (LAS) flows, whereas WC induced a transition from stratified wavy or roll waves to Highly Aerated Slug (HAS) flows, through pseudo-slug.

The slug frequency $\left(f_{\mathrm{s}}\right)$, defined as the number of slugs passing over a period of time, is an important parameter for industrials. Various models have been developed for its estimation [13]. Taitel and Dukler [17] explained that slug frequency is the inverse of the time for a slug to form. Consequently, the slug frequency depends on the slug formation mechanism leading the authors to include such observation in a theoretical model for its prediction. Kadri [33] proposed a probabilistic model based on the assertion that slugs are triggered at the antinodes of a sinusoidal perturbation, along the pipe at the frequency of oscillation of the interface. It should be observed that in general empirical correlations are more used for their convenience in comparison to theoretical models.

According to the literature survey, a well-established model describing the onset of intermittent flow is lacking. In addition, few studies focused on the intermittent flow structures onset constituting the main objective of the present investigation. The analysis was carried out, in a $30 \mathrm{~mm}$ ID pipe, by flow visualizations corroborated by differential pressure signals. The results were compared to available literature data and models. Moreover, the present study was undertaken to provide statistical information on a parameter of a primary interest in the petroleum industry i.e. the slug frequency.

\section{Experimental setup}

The experiments were carried out on the same experimental device described by our previous works [13, 14]. Figure 1 shows the schematic of the device composed of a $30 \mathrm{~mm}$
Table 1. detail of the differential pressure sensor used.

\begin{tabular}{ll}
\hline Type & Freescale MPX2010 \\
Technology & Silicon piezoresistive differential \\
& pressure sensor \\
Pressure range & 0 to $\pm 10000 \mathrm{~Pa}$ \\
Accuracy & $200 \mathrm{~Pa}$ \\
Response time & $1 \mathrm{~ms}$ \\
Voltage output & $\pm 2500 \mathrm{mV}$ \\
\hline
\end{tabular}

ID and $13 \mathrm{~m}$ long pipe, made entirely of transparent acrylic resin to allow flow visualization. The working fluids, water and air, were mixed using a T-mixer, with a vertical downward inlet for the gas and a horizontal run for the liquid. After passing through the pipe, the two-phase mixture was discharged into a tank functioning as a separator. The water was recycled while the air escaped. The gas and liquid flow rates were measured by respectively a rotameter (uncertainly $\pm 1 \%$ ) and an ultrasonic flowmeter (uncertainty $\pm 2 \%$ ).

A camera type Nikon D3400 (maximum resolution $6000 \times 4000$ pixels) was positioned at $5.2 \mathrm{~m}$ downstream the two-phase flow mixer. Two light-projectors were placed behind and on the either side of the camera to provide sufficient light. The images were processed with the GIMP software. Differential pressure signals were recorded from sensors connected between 5.2 and $5.8 \mathrm{~m}$ from the input mixer. The details of the pressure sensors are provided in Table 1. For each run, a signal of duration of $40 \mathrm{~s}$ was acquired. The sampling frequency is equal to $250 \mathrm{~Hz}$.

The experiments were carried out with the following procedure:

- The liquid flow rate is first stabilized and then the gas flow rate is adjusted. 


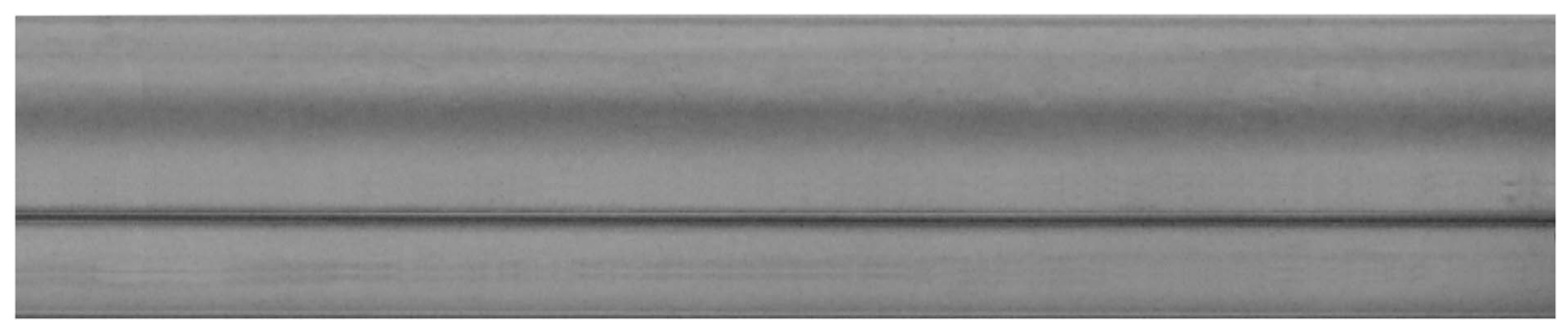

Fig. 2. Example of stratified smooth flow $\left(V_{\mathrm{SL}}=0.047 \mathrm{~m} / \mathrm{s}\right.$ and $\left.V_{\mathrm{SG}}=0.786 \mathrm{~m} / \mathrm{s}\right)$. Flow direction: from left to right.

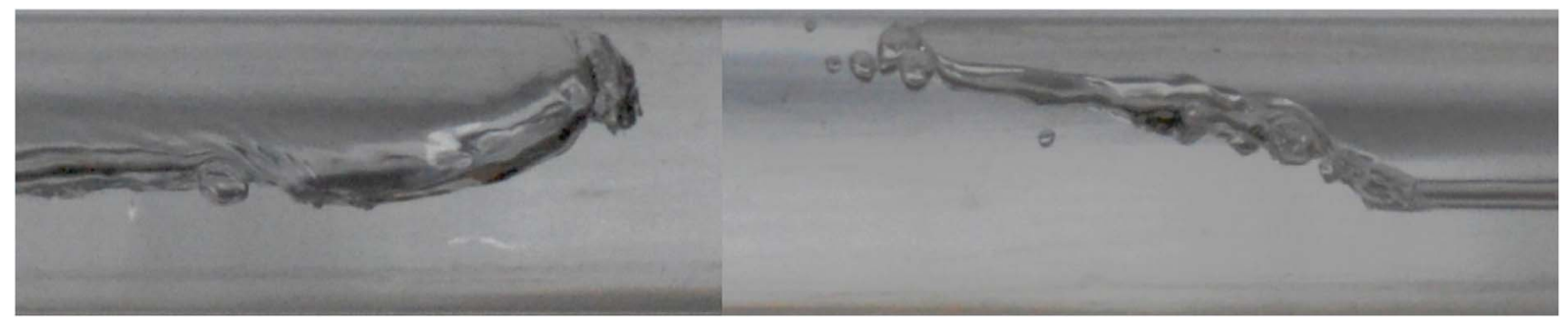

Fig. 3. Example of Plug flow $\left(V_{\mathrm{SL}}=0.071 \mathrm{~m} / \mathrm{s}\right.$ and $\left.V_{\mathrm{SG}}=0.786 \mathrm{~m} / \mathrm{s}\right)$. Flow direction: from left to right.

- Observations and signal acquisitions were done one minute after flow rates adjustments. Indeed, primary observations showed that this time is sufficient for the flow structures stabilization.

\section{Results and discussion}

This study was focused on the intermittent flow onset zone, when the liquid slug appears. The experimental observations and acquisition were carried out for $0.047 \mathrm{~m} / \mathrm{s}<$ $V_{\mathrm{SL}}<0.094 \mathrm{~m} / \mathrm{s}$ and $0.436 \mathrm{~m} / \mathrm{s}<V_{\mathrm{SG}}<3.537 \mathrm{~m} / \mathrm{s}$.

\subsection{Visual observations}

In this section, the photographs of the structure observed in experiments are presented and analyzed. The pictures were taken at $5.2 \mathrm{~m}$ from the inlet mixer which is sufficient length for the formation and stabilization of the so-called structures.

Figure 2 shows a photograph of a perfectly smooth stratified flow for $V_{\mathrm{SL}}=0.047 \mathrm{~m} / \mathrm{s}$ and $V_{\mathrm{SG}}=0.786 \mathrm{~m} / \mathrm{s}$. In this regime, only the lower part of the pipe area section was wetted by the liquid.

Keeping the gas superficial velocity constant, a slight increase in $V_{\mathrm{SL}}$ to $0.071 \mathrm{~m} / \mathrm{s}$ led to the occurrence of the onset of intermittent flow as shown, by the appearance of a liquid slug, in Figure 3. We can observe that the gas pocket ends with a hydraulic jump, followed by a long tail. The presence of a very small amount of air bubbles inside the liquid slug was also noted. These two observations confirmed the plug flow $[11,13,34,35]$. This intermittent flow sub-regime appeared at low superficial gas velocities $[13,36]$. The episodic detachment of air bubbles, occurring at the end of the long tail of the gas pocket, is due to the fact that most interaction, between the gas pocket and the liquid slug, takes place in this zone [37]. The observation of the plug flow in the zone of intermittent flow onset shows the existence of a direct stratified/plug flow transition. This finding contradicts several flow pattern maps [10, 27-29].

The liquid slug in Figure 4, obtained by increasing the superficial gas velocity at $1.572 \mathrm{~m} / \mathrm{s}$, is more aerated and the long tail at the end of the gas pocket disappeared. In addition, bubbles are detached over the entire slug body nose/gas pocket tail interface. These characteristics are typical of a slug flow. Thaker and Banerjee [38] explained that an increase in the superficial velocity of the gas leads to an increase in the relative velocity between the liquid slugs and the liquid film supporting the gas pocket. Consequently, the shear stress at the slug body/gas bubble tail interface is increased and the bubbles entrainment overcomes the surface tension. The entrainment is relatively low, within the studied range of the average gas superficial velocities. This was materialized by the presence of easily distinguishable dispersed bubbles in the liquid slugs. This type of slug flow is called Less Aerated Slug flow (LAS flow) [10, 11, 13].

Increasing the gas superficial velocity up to $2.751 \mathrm{~m} / \mathrm{s}$ while keeping $V_{\mathrm{SL}}$ constant, involves the incursion of more gas into the liquid slugs converting them into pseudo-slugs (Fig. 5). These structures consist of intermittent large waves, touching almost and momentarily the upper section of the pipe [13].

Figure 6 shows an example of Highly Aerated Slug flow (HAS flow) observed by keeping $V_{S G}$ constant while increasing $V_{\mathrm{SL}}$ at $0.082 \mathrm{~m} / \mathrm{s}$. This slug flow sub-regime is characterized by a strong aeration of the liquid slug making the identification of the interface as well as the air bubbles inside it difficult $[10,11,13]$. In this range of liquid superficial velocities, the pseudo-slugs flow with a highly aerated slugs are observed. 


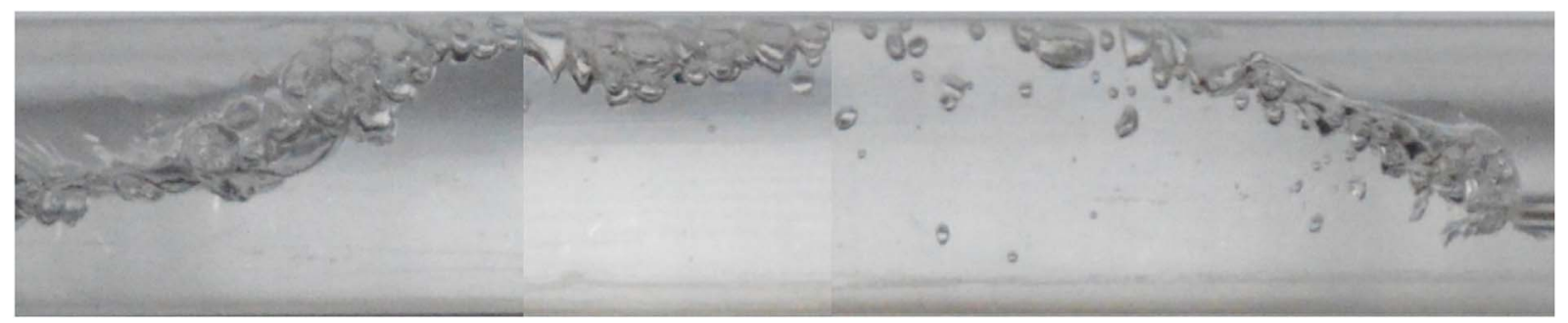

Fig. 4. Example of Less Aerated Slug flow (LAS flow) $\left(V_{\mathrm{SL}}=0.071 \mathrm{~m} / \mathrm{s}\right.$ and $\left.V_{\mathrm{SG}}=1.572 \mathrm{~m} / \mathrm{s}\right)$. Flow direction: from left to right.

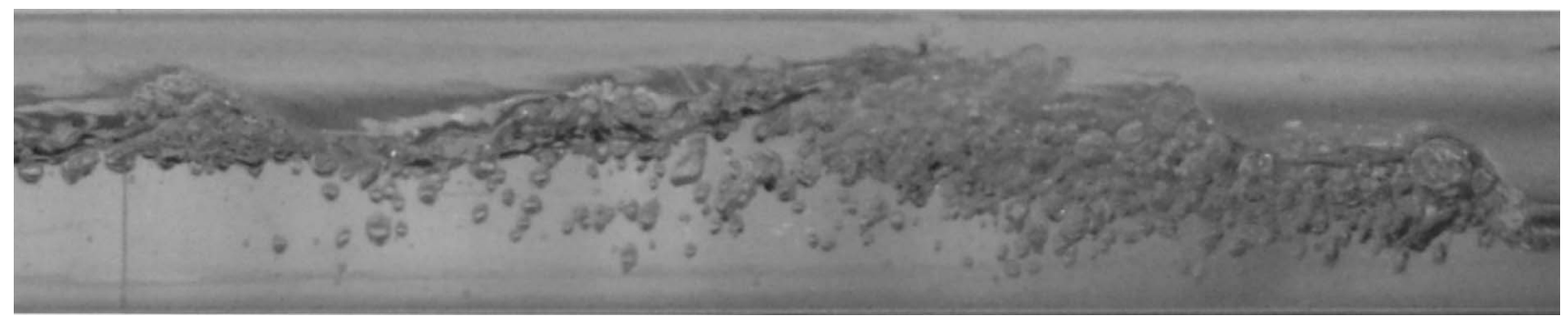

Fig. 5. Example of a pseudo-slug $\left(V_{\mathrm{SL}}=0.071 \mathrm{~m} / \mathrm{s} \mathrm{m} / \mathrm{s}\right.$ and $\left.V_{\mathrm{SG}}=2.751 \mathrm{~m} / \mathrm{s}\right)$. Flow direction: from left to right.

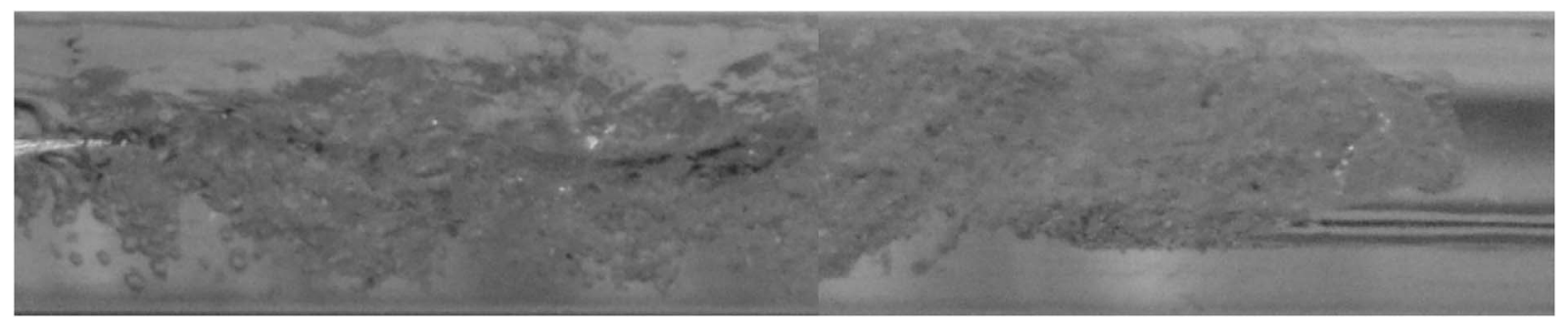

Fig. 6. Example of Highly Aerated Slug flow (HAS flow) $\left(V_{\mathrm{SL}}=0.082 \mathrm{~m} / \mathrm{s}\right.$ and $\left.V_{\mathrm{SG}}=2.751 \mathrm{~m} / \mathrm{s}\right)$. Flow direction: from left to right.

It appears from these photographs that an increase in the gas superficial velocity leads to an increase in the aeration of the liquid slugs, which subsequently results in the appearance of different intermittent flow sub-regimes (Plug flow, LAS flow and HAS flow). It is important to note that these three sub-regimes are present from the onset of slug flow.

\subsection{Onset of intermittent flow}

The conditions of the onset of intermittent flow observed visually in this study, for each type of intermittent flow, are reported in Figure 7. The increase of the gas superficial velocity leads to the initiation of slug formation at lower liquid superficial velocity. This finding is valid only for the plug and LAS flow, which were observed for $V_{\mathrm{SG}}$ below $\sim 2 \mathrm{~m} / \mathrm{s}$. From this critical value, the interface gas-liquid shows undulations with the presence of pseudo-slugs. Thereby, more liquid was required to form the liquid slugs, which will be HAS flow.

In Figure 8, the present results of the onset of intermittent flow are compared with those observed by some works obtained using different pipe diameters. It is noted that an increase in diameter required a higher liquid superficial velocity for the initiation of liquid slugs. The fact that the onset of slug flow in our study occurred at a lower liquid superficial velocity compared to the studies of Thaker and Banerjee (25 mm) [10] and Deendarlianto et al. (26 mm) [12], which were carried out on smaller diameters, is due to the type of inlet mixer. For the present study, a T-mixer was used, which generated greater disturbances, precipitating the formation of slugs than the mixer used in the above-mentioned works. This finding was reported by Fan et al. [24].

The transition line obtained on this study was compared with those proposed by Weisman et al. [23] (Fig. 9a), Cheng et al. [22] and Bhagwat and Ghajar [30] (Fig. 9b). In the first figure, we reported the points where the transition occurred using the ratio gas-to-liquid superficial velocity $\left(V_{\mathrm{SG}} / V_{\mathrm{SL}}\right)$ in abscissa. Whereas the Lockhart-Martinelli parameter $(X)$ was used in Figure 9b. The Gas based Froude number $\left(\mathrm{Fr}_{\mathrm{SG}}\right)$ was used as ordinate in both cases. We can observe that the transition lines obtained in the present study were not well predicted by the three models. The fact that the experimental transition points fall in the area of stratified flow in the first figure, and in the region of 


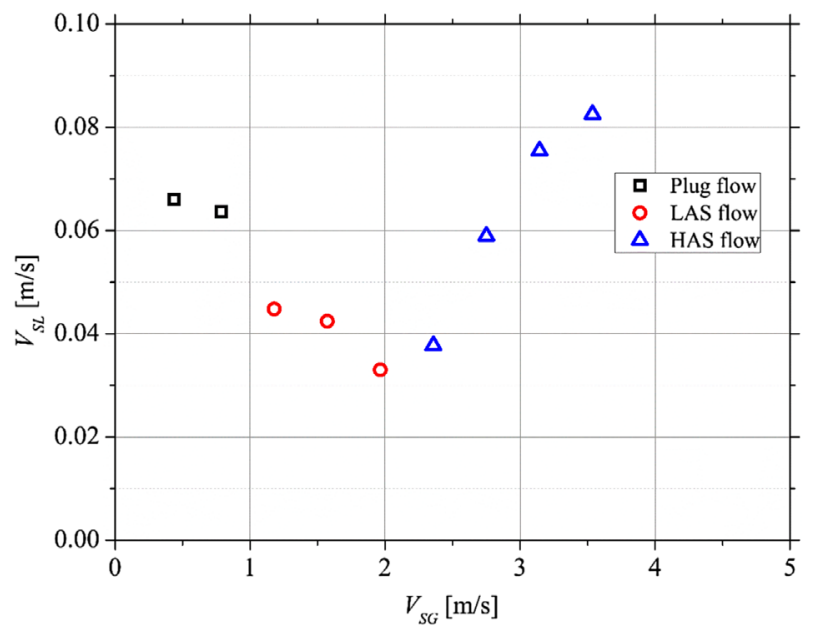

Fig. 7. Condition of onset of intermittent flow for different subregimes.

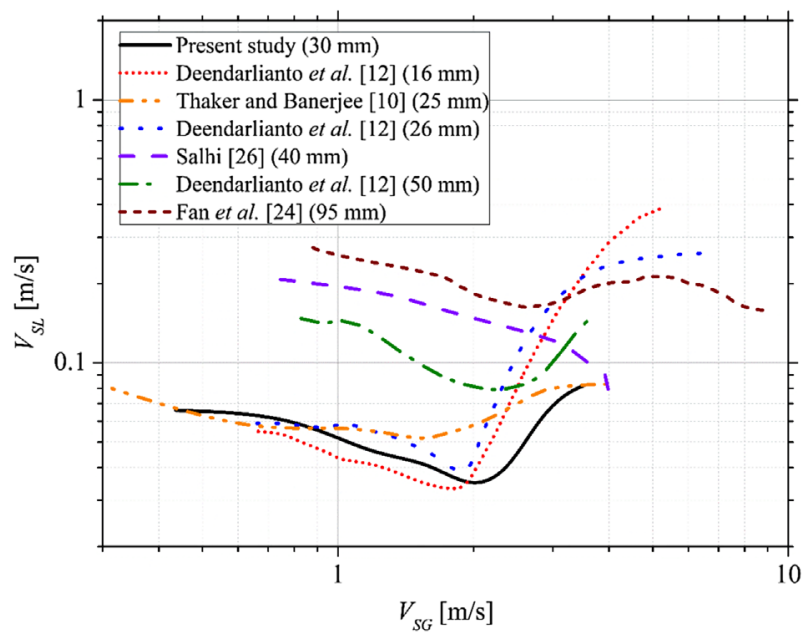

Fig. 8. Condition of onset of slug flow: Comparison with the literature.

intermittent flow in the second figure reveals the limitations of the existing models. Indeed, the development of more consistent models is encouraged to predict this type of transition.

\subsection{Pressure drop signal analysis}

Figure 10 shows the portion of pressure drop signal, as function of time, collected for different conditions of both phases superficial velocities. For smooth stratified flow (Fig. 10a), the pressure drop has a constant value. As reported in Section 3.1, an increase in the liquid superficial velocity leads to the onset of intermittent flow, resulting in the appearance of peaks in the pressure drop signals (Fig. 10b) [13, 14, 34]. We note the low number of slugs ( 1 in this case) flowing during a period of $20 \mathrm{~s}$. This feature is typical of the onset of intermittent flow sub-regime. Increasing the gas

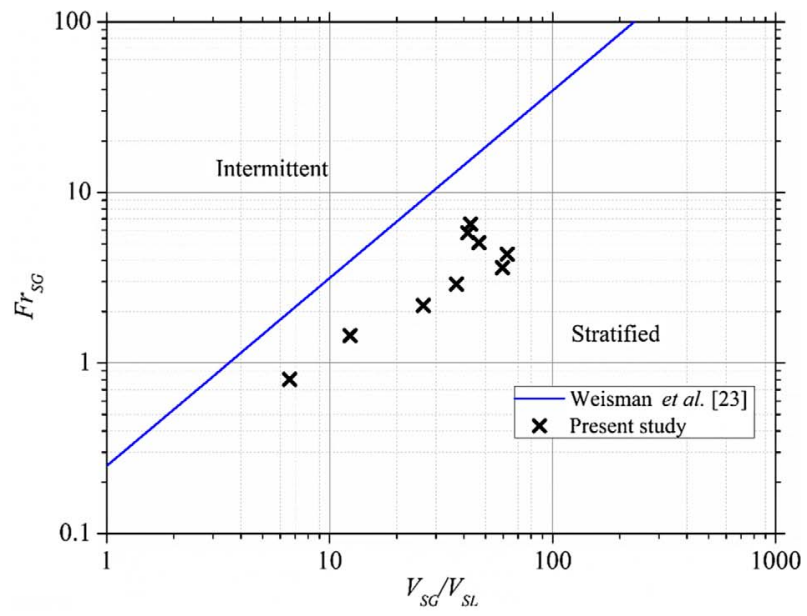

(a)

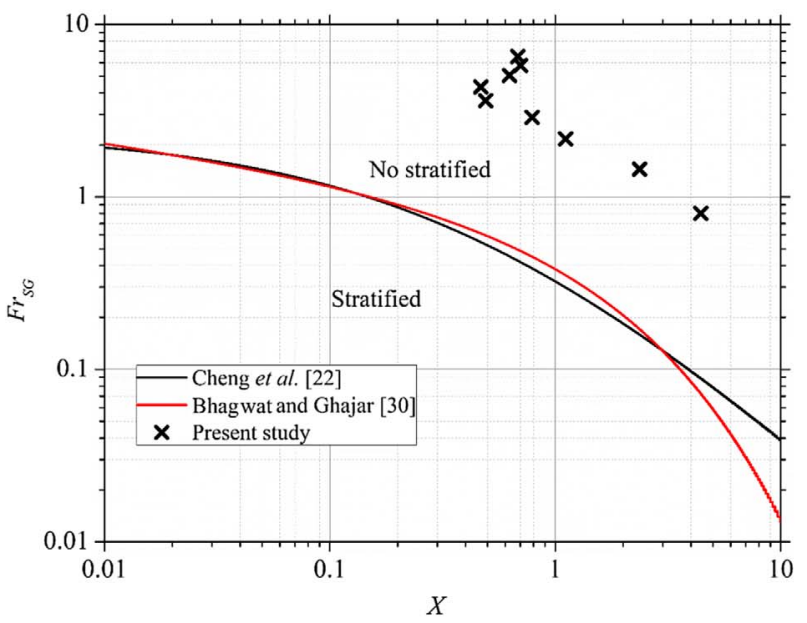

(b)

Fig. 9. Comparison between experimental transitions points and different available models.

superficial velocity induces a transition from plug flow to LAS flow, which will be manifested by the appearance of peaks with greater amplitude (Fig. 10c). The passage of waves between the pressure taps was also recorded. Meanwhile, the wave generates fewer fluctuations, compared to liquid slugs [34]. Figure 10d shows the signal collected in the case of a highly aerated slug following a pseudo-slug. We can deduce that the passage of pseudo-slug causes also the appearance of peaks in the pressure drop signal. However, the amplitudes of this structure is less important compared to those of liquid slug.

\subsection{Slug frequency}

As recommended by Arabi et al. [13], the values of slug frequency were extracted from the dominant frequency obtained by applying the Power Spectral Density $(P S D)$ on the pressure drop time signal. The detail of this method was given by Arabi et al. $[13,34]$. The obtained slug frequencies are depicted in Figure 11 using the gas based 


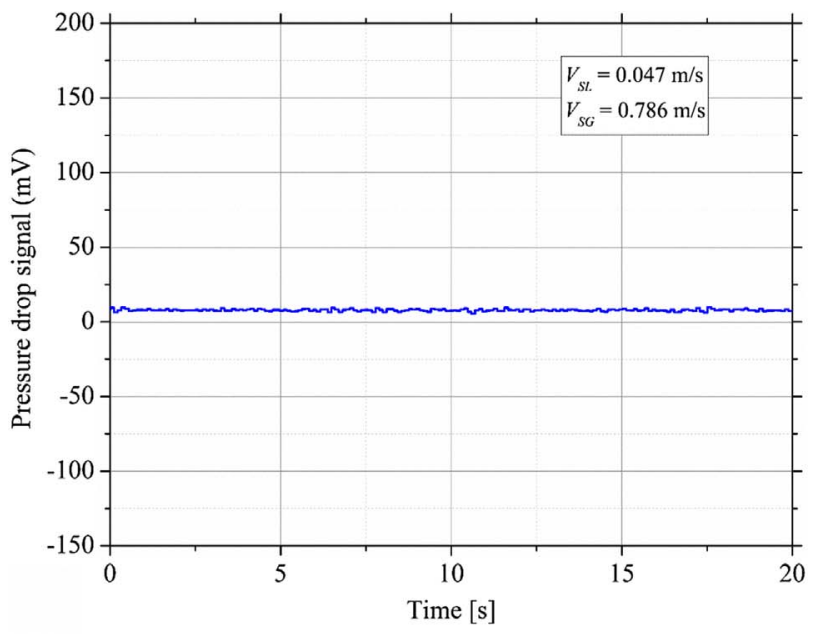

(a)

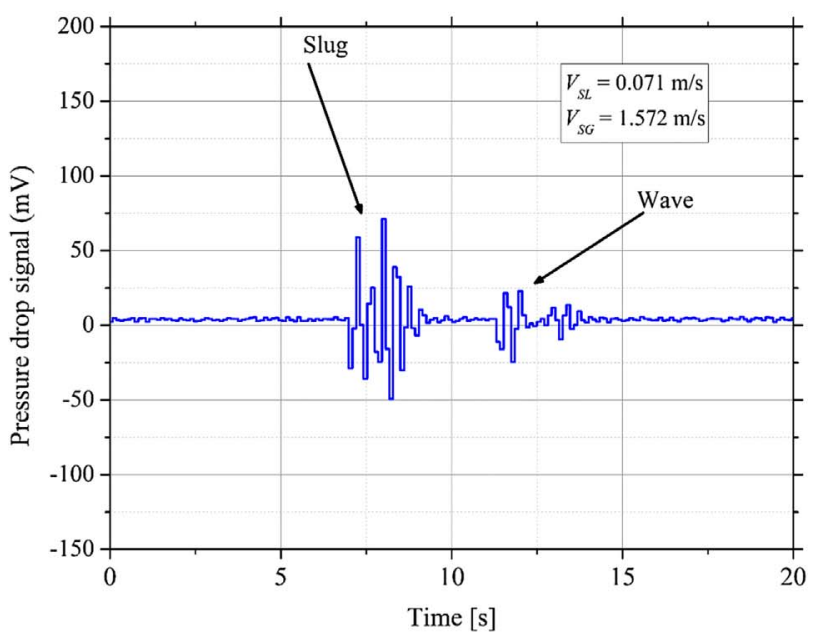

(c)

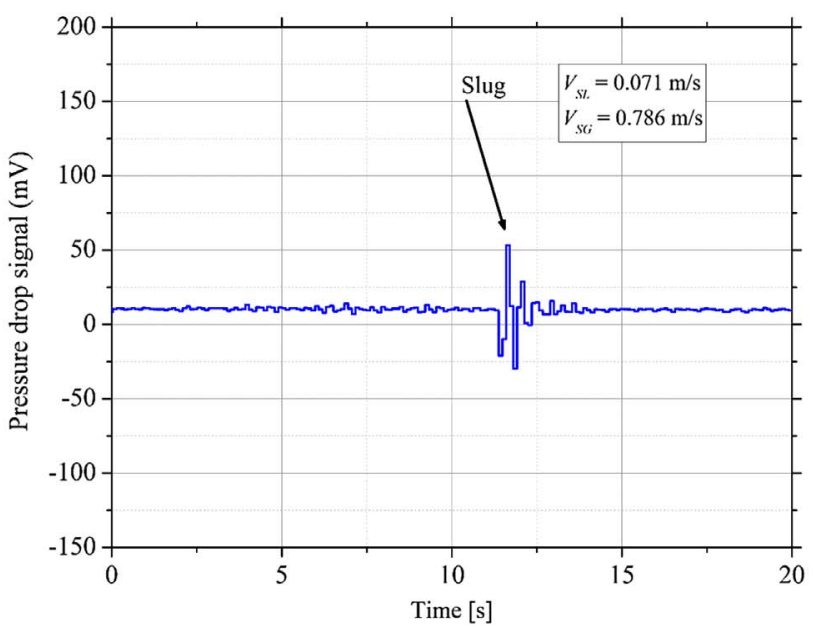

(b)

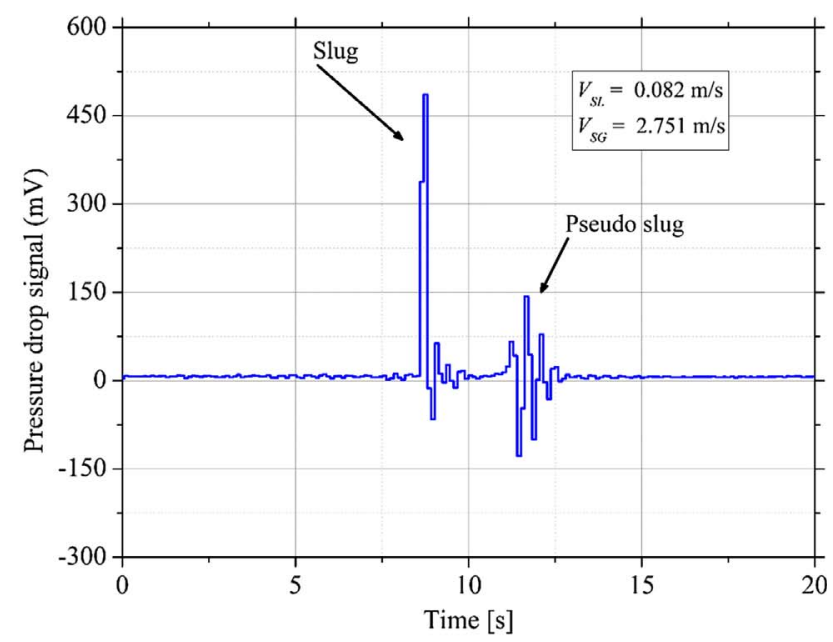

(d)

Fig. 10. Examples of pressure drop signal collected for different conditions.

Strouhal number $\left(\mathrm{St}_{\mathrm{G}}\right)$ (Eq. (10)) as a function of the input liquid fraction $\left(\lambda_{\mathrm{L}}\right)$ (Eq. (11)). Indeed, several studies $[13,39-41]$ showed that this type of representation well correlates the slug frequency. The data of Thaker and Banerjee [31], obtained with $25 \mathrm{~mm} \mathrm{ID,} \mathrm{are} \mathrm{also} \mathrm{shown.} \mathrm{The} \mathrm{blue,} \mathrm{red}$ and green lines represent correlation curves of Fossa et al. [39], Wang et al. [40], and Arabi et al. [41], respectively.

$$
\begin{gathered}
\mathrm{St}_{\mathrm{G}}=\frac{f_{\mathrm{S}} D}{V_{\mathrm{SG}}}, \\
\lambda_{\mathrm{L}}=\frac{V_{\mathrm{SL}}}{V_{\mathrm{SG}}+V_{\mathrm{SL}}} .
\end{gathered}
$$

It is clear from Figure 11 that the three correlations overestimate the results due to the fact that, at the onset of intermittent flow, the number of slugs is low. This observation shows that the correlations developed for the slug frequency

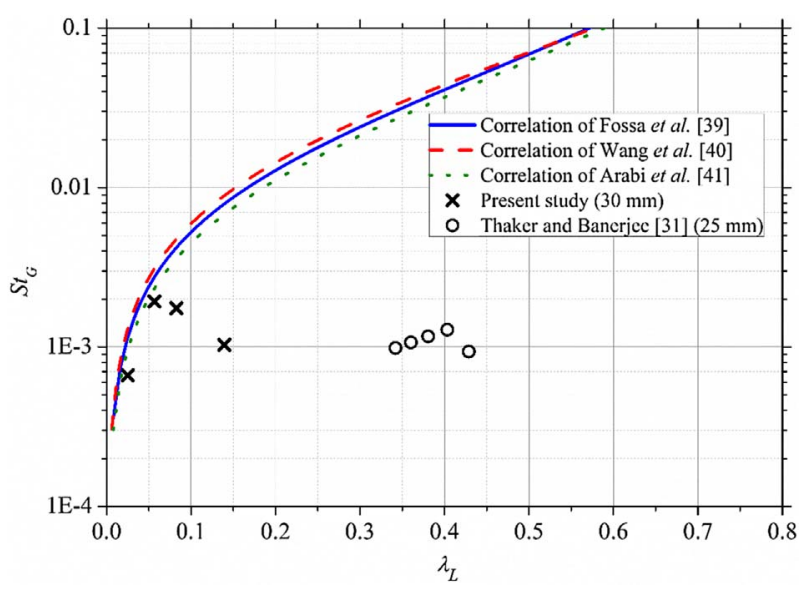

Fig. 11. Comparison between experimental data of slug frequency with available correlations. 
for the intermittent regime are not valid at the onset of intermittent flow.

\section{Concluding remarks}

The present experimental investigation, based on flow visualization and pressure drop signals, carried on the onset of intermittent flow in a $30 \mathrm{~mm}$ ID pipe led to the following conclusions:

- The liquid superficial velocity $V_{\mathrm{SL}}$ plays a great role on the formation of intermittent flow.

- The gas superficial velocity $V_{\mathrm{SG}}$ has an effect on the liquid slug aeration, leading to the apparition of different intermittent sub-regimes flows (Plug flow, LAS flow and HAS flow).

- For high gas flow rates, a higher liquid superficial velocity $V_{\mathrm{SL}}$ is required for slug initiation.

- The comparison of the experimental results of onset of intermittent flow with those obtained by various authors showed the major role of the pipe diameter in the onset of a slug.

- The appearance of liquid slugs and pseudo-slugs leads to an increase in the pressure drop, which is materialized by the occurrence of peaks in the time signals of pressure drop.

- Slug frequencies obtained with the correlations developed for intermittent regimes showed discrepancies when applied to the onset of intermittent flow.

In regard to the obtained results, it appears that additional studies, focusing on the sub-regimes present in the onset of intermittent flow, are to be carried out. Using others pipe diameters as well as different working fluids will allow a better understanding of the phenomena observed during the stratified/intermittent flow transition. In addition, it will enable the development of more reliable theoretical models to study such transition. These models will notably be used in multiphase flow simulation codes.

Acknowledgments. This work was partially funded by the project SONATRACH-U.S.T.H.B. (project number: SH-U.S.T. H.B. RD No1).

\section{References}

1 Shi S., Wu X., Han G., Zhong Z. (2019) Study on the gasliquid annular vortex flow for liquid unloading of gas well, $O i l$ Gas Sci. Technol. - Rev. IFP Energies nouvelles 74, 82.

2 Amaya-Gómez R., López J., Pineda H., Urbano-Caguasango D., Pinilla J., Ratkovich N., Muñoz F. (2019) Probabilistic approach of a flow pattern map for horizontal, vertical, and inclined pipes, Oil Gas Sci. Technol. - Rev. IFP Energies nouvelles $\mathbf{7 4}, 67$.

3 Duan J.M., Wang W., Zhang Y., Zheng L.J., Liu H.S., Gong J. (2013) Energy equation derivation of the oil-gas flow in pipelines, Oil Gas Sci. Technol. - Rev. IFP Energies nouvelles 68, 2, 341-353.
4 Tran Q.H., Ferre D., Pauchon C., Masella J.P. (1998) Transient simulation of two-phase flows in pipes, Revue de l'Institut Français du Pétrole 53, 6, 801-811.

5 Henriot V., Duret E., Heintzé E., Courbot A. (2002) Multiphase production control: Application to slug flow, Oil Gas Sci. Technol. - Rev. IFP Energies nouvelles 57, 1, 87-98.

6 Duan J., Li J., Liu H., Gu K., Guan J., Xu S., Gong J. (2018) A model of wax deposition under oil-gas two-phase stratified flow in horizontal pipe, Oil Gas Sci. Technol. - Rev. IFP Energies nouvelles $\mathbf{7 3}, 80$.

7 Ghajar A.J. (2020) Two-phase gas-liquid flow in pipes with different orientations, Springer International Publishing.

8 Salhi Y., Si-Ahmed E.K., Legrand J., Degrez G. (2010) Stability analysis of inclined stratified two-phase gas-liquid flow, Nucl. Eng. Des. 240, 5, 1083-1096.

9 Ferré D. (1979) Écoulements diphasiques à poches en conduite horizontale, La Houille Blanche 6-7, 378-381.

10 Thaker J., Banerjee J. (2015) Characterization of two-phase slug flow sub-regimes using flow visualization, J. Petrol. Sci. Eng. 135, 561-576.

11 Thaker J., Banerjee J. (2016) Influence of intermittent flow sub-patterns on erosion-corrosion in horizontal pipe, $J$. Petrol. Sci. Eng. 145, 298-320.

12 Deendarlianto, Rahmandhika A., Dinaryanto O., Widyaparaga A., Indarto (2019) Experimental study on the hydrodynamic behavior of gas-liquid air-water two-phase flow near the transition to slug flow in horizontal pipes, Int. J. Heat Mass Transf. 130, 187-203.

13 Arabi A., Salhi Y., Zenati Y., Si-Ahmed E.K., Legrand J. (2020) On gas-liquid intermittent flow in a horizontal pipe: Influence of sub-regime on slug frequency, Chem. Eng. Sci. 211, 115251.

14 Arabi A. (2019) Contribution à l'étude du comportement d'un écoulement diphasique dans une conduite en présence d'une singularité, PhD thesis, USTHB, Algiers, Algeria.

15 API (2016) API 579-1/ASME FFS-1 2016 Fitness-ForService, American Petroleum Institute, Washington, DC.

16 Dukler A.E., Hubbard M.G. (1975) A model for gas-liquid slug flow in horizontal and near horizontal tubes, Industrial 86 Engineering Chemistry Fundamentals 14, 4, 337-347.

17 Taitel Y., Dukler A.E. (1977) A model for slug frequency during gas-liquid flow in horizontal and near horizontal pipes, Int. J. Multiphase Flow 3, 6, 585-596.

18 Wallis G.B., Dobson J.E. (1973) Prediction of the initiation of slugs with linear stability criterion, Int. J. Multiphase Flow 1, 173-193.

19 Taitel Y., Dukler A.E. (1976) A model for predicting flow regime transitions in horizontal and near horizontal gasliquid flow, AIChE J 22, 1, 47-55.

20 Hurlburt E.T., Hanratty T.J. (2002) Prediction of the transition from stratified to slug and plug flow for long pipes, Int. J. Multiphase Flow 28, 5, 707-729.

21 Miao S., Hendrickson K., Liu Y. (2019) Slug generation processes in co-current turbulent-gas/laminar-liquid flows in horizontal channels, J. Fluid Mech. 860, 224-257.

22 Cheng S.C., Wong Y.L., Groeneveld D.C. (1988) CHF prediction for horizontal flow, in: International Symposium on Phase Change Heat Transfer, Chongqing, Sichuan, China, May 20-23, 1988, pp. 211-215.

23 Weisman J., Duncan D.G.J.C.T., Gibson J., Crawford T. (1979) Effects of fluid properties and pipe diameter on twophase flow patterns in horizontal lines, Int. J. Multiphase Flow 5, 6, 437-462. 
24 Fan Z., Lusseyran F., Hanratty T.J. (1993) Initiation of slugs in horizontal gas-liquid flows, AIChE J. 39, 11, 1741-1753.

25 Woods B.D., Hanratty T.J. (1999) Influence of Froude number on physical processes determining frequency of slugging in horizontal gas-liquid flows, Int. J. Multiphase Flow 25, 6-7, 1195-1223.

26 Salhi Y. (2010) Contributions théorique et expérimentale à l'étude des phénomènes de transition d'un écoulement stratifié à l'écoulement poche/bouchon dans une conduite horizontale en présence de singularité, PhD Thesis, USTHB Algiers, Algeria.

27 Vaze M.J., Banerjee J. (2012) Prediction of liquid height for onset of slug flow, Can J. Chem. Eng. 90, 5, 1295-1303.

28 Ghajar A.J., Tang C.C. (2010) Importance of non-boiling two-phase flow heat transfer in pipes for industrial applications, Heat Trans. Eng. 31, 9, 711-732.

29 Vaze M.J., Banerjee J. (2011) Experimental visualization of two-phase flow patterns and transition from stratified to slug flow, Proc. Inst. Mech. Eng. C: J. Mech. Eng. Sci. 225, 2, 382-389.

30 Bhagwat S.M., Ghajar A.J. (2015) An empirical model to predict the transition between stratified and non-stratified gas-liquid two-phase flow in horizontal and downward inclined pipes, Heat Trans. Eng. 36, 18, 1489-1498.

31 Thaker J., Banerjee J. (2017) Experimental investigations on onset of slugging in horizontal air-water two-phase flow, in: Fluid Mechanics and Fluid Power-Contemporary Research, Springer, New Delhi, pp. 157-166.

32 Dinaryanto O., Prayitno Y.A.K., Majid A.I., Hudaya A.Z., Nusirwan Y.A., Widyaparaga A. (2017) Experimental investigation on the initiation and flow development of gas-liquid slug two-phase flow in a horizontal pipe, Exp. Therm. Fluid Sci. 81, 93-108.
33 Kadri U. (2014) A probabilistic approach for predicting average slug frequency in horizontal gas/liquid pipe flow, Oil Gas Sci. Technol. - Rev. IFP Energies nouvelles 69, 2, 331-339.

34 Arabi A., Salhi Y., Si-Ahmed E.K., Legrand J. (2018) Influence of a sudden expansion on slug flow characteristics in a horizontal two-phase flow: a pressure drop fluctuations analysis, Meccanica 53, 13, 3321-3338.

35 Zitouni A.H., Arabi A., Salhi Y., Zenati Y., Si-Ahmed E.K., Legrand J. (2021) Slug length and frequency upstream a sudden expansion in gas-liquid intermittent flow, Exp. Comput. Multiphase Flow 3, 2, 124-130.

36 Thaker J., Banerjee J. (2016) On intermittent flow characteristics of gas-liquid two-phase flow, Nucl. Eng. Des. 310, 363-377.

37 Talley J.D., Worosz T., Kim S., Buchanan J.R. Jr. (2015) Characterization of horizontal air-water two-phase flow in a round pipe part I: Flow visualization, Int. J. Multiphase Flow 76, 212-222.

38 Thaker J., Banerjee J. (2017) Transition of plug to slug flow and associated fluid dynamics, Int. J. Multiphase Flow 91, 63-75.

39 Fossa M., Guglielmini G., Marchitto A. (2003) Intermittent flow parameters from void fraction analysis, Flow Meas. Instrum. 14, 4-5, 161-168.

40 Wang X., Guo L., Zhang X. (2007) An experimental study of the statistical parameters of gas-liquid two-phase slug flow in horizontal pipeline, Int. J. Heat Mass Trans. 50, 11-12, 2439-2443.

41 Arabi A., Ragui K., Salhi Y., Filali A. (2020) Slug frequency for a gas-liquid plug flow: Review and development of a new correlation, Int. Commun. Heat Mass Trans. 118, 104841 . 